\title{
Research on Teaching Mode of Building Architecture Based on Digital Technology
}

\author{
Neng Zhang*1 , Lingzhi Wang ${ }^{1}$ \\ College of Pipeline and Civil Engineering, China University of Petroleum (East China), Qingdao, 266580, China. \\ 20060077@upc.edu.cn
}

\begin{abstract}
This paper analyzes the present situation of traditional teaching of building architecture and the problems existing in the process of reform. Based on the OBE output-oriented concept and aiming at cultivating excellent engineers, relying on the Virtual simulation Experiment Center of China University of Petroleum (East China), this paper explores the digital teaching mode of building architecture course, proposes the construction and integration measures of virtual module resource base, and discusses the assessment method based on virtual simulation +BIM. This paper analyzes the effects and advantages of the curriculum reform of building architecture, and shows that digital technology plays an important role in the teaching of building architecture.
\end{abstract}

Keywords: Digital technology, Teaching model, Resource bank construction, Building architecture.

\section{INTRODUCTION}

Building Architecture is a compulsory course for civil engineering majors, which plays an important role in professional theoretical courses. It is a link between civil engineering and engineering management majors and architecture. It is a cross-disciplinary course with strong comprehensiveness and many knowledge points. Under the OBE output-oriented education concept, the traditional teaching mode of PPT+ imagination screen is no longer suitable for the current situation, so it is imperative to explore a teaching mode with adaptability and promotion value. Innovative teaching exploration should also appear at the same time, such as the scientific research innovation mode [1] under the guidance of the tutor system and the exploration of the course examination mode [2]. In the exploration of teaching mode, virtual simulation technology is widely used.

\section{APPLICATION BACKGROUND ANALYSIS OF DIGITAL TECHNOLOGY}

In the Ministry of Education to carry out the model of virtual simulation experiment teaching under the background of project construction, various universities actively explore new teaching mode combined with virtual reality, different subjects and different major in building architecture based on "Internet + " teaching material optimization[3], the optimization study of simulation technology[4-6]and web development[7] aand other experiments and teaching application research. A large number of outstanding achievements and cases emerged, but there are also many deficiencies and urgent problems to be solved. (1) Serious homogenization. Teaching resources are mostly purchased from the Internet or platform, and lack differentiation and originality. (2) The phenomenon of large quantity and low quality is serious. A large number of low-precision 3D models are used in teaching, which makes it difficult to carry out in-depth teaching design and teaching research. Virtual simulation teaching is mainly based on 3D virtual display in order to make up for the lack of sensory cognition. (3) Lack of promotion value. Virtual simulation teaching projects mostly appear in the form of single machine, lacking a complete system, module fragmentation and sharing mechanism[8-10], so it has no reference value.

The Department of Architecture, China University of Petroleum (east China) has established Qingdao Virtual Simulation Experiment Center through university-enterprise cooperation and education. At present, it has completed the integration of VR virtual simulation technology, BIM information technology, uav aerial photography and a series of new technologies in teaching. The teaching mode of Building Architecture innovatively builds a public platform according to the course cluster, creates a BIM+ virtual simulation digital platform, and realizes a complete system of 
experimental teaching resource management and course resource information sharing. Relying on Qingdao Virtual Simulation Experiment Center, the course cluster is composed of architectural Design, Architectural Construction and Building Architecture, building architecture teaching system and teaching mode based on digital technology is constructed, and the OBE education concept of "output-oriented" is practiced.

\section{DIGITAL TECHNOLOGY TEACHING PLATFORM CONSTRUCTION}

UE4 (Unreal Engine 4) virtual Engine and VR technology is a computer simulation system that can experience the virtual world. It focuses on creating a system simulation combining $3 \mathrm{~d}$ dynamic view with multi-source information fusion and entity behavior to form an interactive and immersive experience. BIM model is the carrier of highly integrated building comprehensive information, and BIM technology can intuitively reflect the building data carried behind the building model. Another feature of BIM is the linkage of its model. Problems can be found in time and adjustments can be made during the modeling process, which is also one of the advantages of BIM technology in teaching and training. The two advantages complement each other, effectively make up for the traditional teaching method of single teaching, poor interaction and other problems.

The course "Building Architecture" builds building and construction information resource library and function module resource library in the virtual simulation center, and carries out collaborative education project cooperation with enterprises to jointly develop virtual simulation teaching resource platform (Fig.1). In virtual simulation teaching, the role of students has changed. They are no longer passive learners of listeners, but designers of virtual buildings, participants of teaching links, who conduct exploratory learning in virtual construction and stimulate students' creative potential.

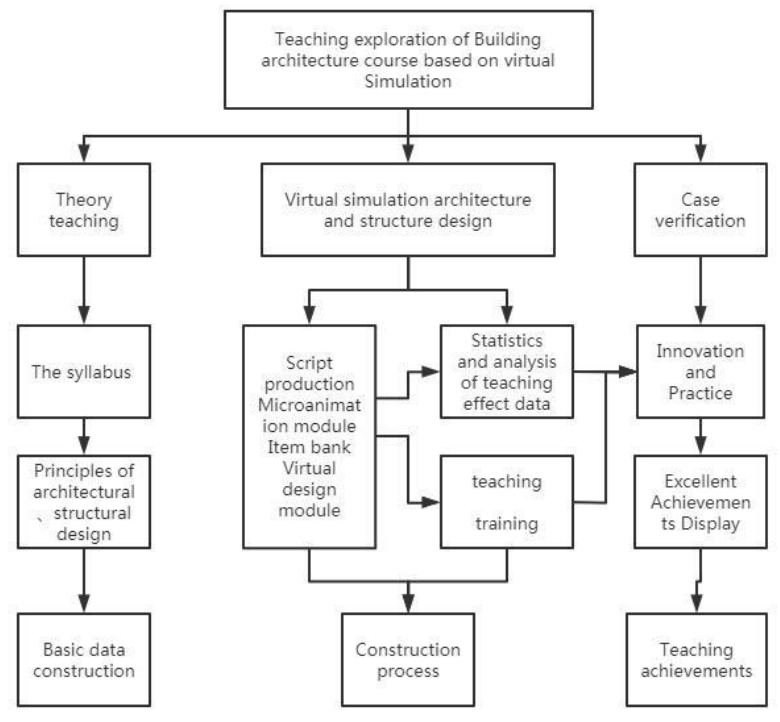

Figure 1 Virtual simulation teaching mode

The development of teaching includes three links: theoretical teaching, virtual design and practical innovation. Each link is complementary and the teaching content is progressive. The theoretical teaching integrates the basic theory of architectural design, key and difficult knowledge points, integrates the courses of architectural design, architectural construction and other clusters, optimizes the knowledge system, builds the building and construction information resource base, selects typical buildings and general construction practices, establishes $3 \mathrm{~d}$ digital model, and introduces the model into BIM information system. In the process of editing the virtual environment of the model with UE4 virtual engine, the knowledge points of building construction are inserted to make VR scenes of building and construction. In the classroom practice, students wear head-display and operation controller on VR interactive devices to learn knowledge points in a virtual environment.

The virtual design part focuses on the teaching organization of architectural design and structural design. First of all, the resource bank of functional modules is set up for civil architecture and building structure, and the building space is classified and summarized, and the basic space unit modules including flat, vertical, section and 3D space model are set up, at the same time, the architectural structure function modules involved in the course of building architecture are built by referring to the architectural structure atlas, and then the students take the basic modules from the platform for architectural design or structural design, complete the understanding and mastery of knowledge in the virtual design, and give play to their creativity in the design.

Practical innovation is the continuation and deepening of the virtual design link. By combining with the engineering practice project based on BIM 
technology, the problems found in the virtual design link and the results of innovation are verified in the engineering practice. Practice and innovation combined with college students' innovation and entrepreneurship training program, the topic selection source is from teachers' research projects, or students can choose the topic by themselves, and the topic selection direction is based on the current hot issues in engineering and teaching research issues. In the teaching process, teachers are no longer simple lecturers, but co-participants and organizers of scheme design, and guides of design innovation.

\section{INNOVATION OF EXAMINATION MODE UNDER THE BACKGROUND OF DIGITAL TECHNOLOGY}

The evaluation mechanism of house architecture based on virtual simulation is more flexible and comprehensive, and the evaluation criteria are more diversified. Meanwhile, it pays attention to cultivating innovative works and achievements in teaching practice, and actively promotes the transformation of achievements by cooperating with enterprises. Assessment forms are divided into written examination, process assessment, online assessment, offline practice and so on.

Instead of objective questions based on memory, the written exam expands subjective questions based on innovation and speculation, focusing on the ability to solve problems in building space shaping and construction. Guided by training the ability to solve practical problems, knowledge points come from textbooks, but the difficulty is set higher than textbooks.

The process assessment is based on the cloud classroom platform of Petroleum University, absorbs excellent teaching resources from the network, completes the teaching requirements through students' independent learning, realizes the transformation of different dimensions of teaching in time and space, and shapes students' self-learning, problem discovery, problem analysis and problem solving abilities.

The online assessment of theoretical teaching is carried out in the constructed functional module database, and the corresponding assessment unit is selected on the virtual simulation platform. The answers are completed in the virtual world by means of design drawing, problem solving and command operation (Fig.2).

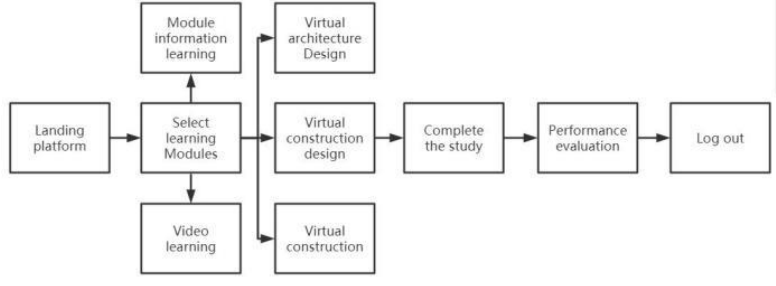

Figure 2 Virtual simulation practice

Offline practice relies on teachers' scientific research projects, carries out curriculum design of building architecture and innovation and entrepreneurship training programs for college students by guiding students to apply BIM technology, carries out assessment of BIM application and comprehensive practical ability, and pays attention to the improvement of the difficulty of assessment and the collaborative education of industry, university and research.

The whole assessment process follows OBE's output-oriented education philosophy, and establishes a long-term and effective continuous improvement mechanism through achievement objective assessment and achievement degree analysis. Problems and deficiencies are found according to feedback information, and teaching content, teaching methods and teaching means are adjusted in real time.

\section{TEACHING EFFECT EVALUATION}

\subsection{Organic integration of theoretical teaching and practical teaching}

Building architecture based on virtual simulation teaching organization, teaching process optimization to architecture design and architecture, computer graphics, and other courses, using the theory of virtual simulation technology to practical teaching and teaching organic integration, effectively promoted the deep change of teaching ideas, methods, means and theory teaching don't have to be limited to the blackboard and PPT, Practice teaching does not need to go deep into the enterprise and the site to realize the seamless connection between theory teaching and practice teaching. Through the analysis of the practical teaching effect, it can be seen that the curriculum objectives required by the syllabus are highly achieved and the teaching effect is excellent.

\subsection{Integration of teaching development from multiple perspectives}

Teaching content in line with the requirements of professional personnel training is the guarantee of teaching quality. There are some problems in the traditional teaching system of building architecture, such as unclear teaching objectives, lack of corresponding relationship between assessment process 
and index points, and single teaching means. OBE multi-means teaching based on virtual simulation accord with school training school idea, stick to the syllabus, output oriented, and the integration of social demand, practice throughout, the attention paid to developing student's innovative, combined with practical engineering, increase the virtual design and innovation research teaching, to train qualified personnel with creative thinking; At the same time, the development of new technology provides a better platform and more means for the teaching of building architecture. Knowledge points are no longer one-way output by teachers. Virtual simulation and VR technology provide the possibility of two-way interaction between teachers and students. Students also strengthen their cognition, improve their interest in learning and improve their independent learning ability in the immersive experience. The problems in the process of knowledge transmission and skill teaching are also conducive to teachers' continuous in-depth research on theoretical knowledge and better integration of virtual reality technology and engineering practice.

\section{CONCLUSION}

The application of virtual simulation technology in the teaching of "Building Architecture" has greatly improved and promoted the teaching means, promoted the optimization and rational layout of the course structure, realized the three-dimensional knowledge point and visual display, and strengthened the integrity of the knowledge system. Virtual simulation technology realizes the high integration of theory teaching and practice teaching, promotes theory and practice simultaneously, focuses on cultivating students' innovative spirit engineering quality and engineering practice ability, and effectively improves the teaching quality. Therefore, it has important theoretical significance and popularization value.

\section{PROJECT}

The first Batch of Industry-University Cooperative Education Project in 2021 (Project No.: 202101185007)

\section{REFERENCES}

[1] Xia Yuanping, NIE Yunju, Cheng Penggen. Research and Practice on talent training mode of geographic information science in local Universities under tutor system [J]. College Education, 2020 (11) : 34-38.

[2] Liu Junwei, WANG Chunling. Research on the Reform and Practice of Non-standard Answer Test of Tour Guide Business Course [J]. Journal of yunnan university (natural science), 2020,42 (S1) : 88-91

[3] Dang Manli, ZHANG Weixi. Research on three-dimensional Teaching Materials of Building Architecture based on "Internet + " [J]. Journal of Taiyuan City Polytechnic, 2021 (7) : 117-119

[4] He Zhankui, Huang Tao. Exploration of Virtual Simulation Experiment Teaching Project Construction [J]. Experimental technology and management, 2018,35 (2) : 108-111.

[5] the exemption. Research and implementation of computer network virtual experiment system based on ASP.NET [D]. Chengdu: University of Electronic Science and Technology of China, 2009.

[6] Yang Minsheng, Li Jianqi, Mei Binyun. Construction and Practice of Virtual Simulation Experiment Teaching System [J]. Information Systems Engineering, 2016 (11) : 97-99.

[7] Zhang Nengli, Xie Jia, Yang Xinquan. Application of ASP.NET in web development [J]. Computer and digital engineering, 2005,33 (6) : 83-86.

[8] Hu Jinhong, Li Hongfei, Huang Tao. Research on Open Sharing Mechanism of Virtual Simulation Experiment Teaching Resources in Colleges and Universities [J]. Laboratory research and exploration, 2015,34 (2) : 140-144.

[9] Zhu Kerong. Problems and Thoughts on the Construction of Virtual Simulation Experimental Teaching Center for Liberal Arts [J]. Modern Education Management, 2016 (1) : 87-91.

[10] Wang Weiguo. Thinking and Suggestion on the Construction of Virtual Simulation Experiment Teaching Center [J]. Laboratory research and exploration, 2013,32 (12) : 5-8. 